\title{
Profile of Beneficiaries Attending DOTS Centre of A Tertiary Care Hospital of Jharkhand
}

\author{
Dr. Abhishek Kumar ${ }^{1}$, Dr. Mithilesh Kumar ${ }^{2}$, Dr. Vivek Kashyap ${ }^{3}$, \\ Dr. Swati Shikha ${ }^{4}$ \\ ${ }^{1,4}$ Junior Resident, ${ }^{2}$ Assistant Professor, ${ }^{3}$ Prof. And Head, Department Of PSM, Rajendra Institute Of Medical \\ Sciences, Ranchi.
}

\begin{abstract}
:
Background: India has the highest burden of tuberculosis in the world accounting for one-fourth of the estimated global incident TB cases. DOTS (Directly observed treatment short course) chemotherapy is defined as a strategy to ensure cure from tuberculosis by providing the most effective medicines and confirming that it is taken. Objectives: This study aims to describe the socio-demographic profile and smoking \& drinking habits of patients attending DOTS centre of Rajendra Institute of Medical Sciences (RIMS), Ranchi. Materials and Methods: This is a cross sectional hospital based study. All registered TB patients coming to DOTS centre of RIMS, Ranchi during our study period and willing to participate in study were included. Duration of study was 3 months. Total sample size for this period was 211. Templates were generated in MS Excel and data analysis was done using SPSS software.

Result and conclusion: After analysis of 211 subjects it was found that majority were males (71.57\%) in the age group 21-40 years (48.82\%) belonging to non tribal communities $(81.04 \%)$ having literacy level of primary grade(43.60\%). Overcrowding accounted to $68.25 \%$ cases. Smokers accounted to $56.40 \%$ cases whereas alcoholics were $42.19 \%$. TB is far more common in non tribal males in the age group 20-40. Half of the cases are smokers.
\end{abstract}

Keywords: Profile, DOTS, TB.

\section{Introduction}

Tuberculosis is completely curable through short-course chemotherapy. Treating TB cases who are sputum-smear positive (and who can therefore spread the disease to others) at the source, it is the most effective means of eliminating TB from a population.

According to WHO Global TB Report, 2015, out of estimated global annual incidence of 9.6 million TB cases, 2.2 million were estimated to have occurred in India. ${ }^{1}$

DOTS (Directly Observed Treatment Short Course) is defined as a strategy to ensure cure by providing the most effective medicine and confirming that it is taken. DOTS is the internationally recommended strategy for TB control that has been recognized as a highly efficient and cost-effective strategy. DOTS comprises five components which are Sustained political and financial commitment, Diagnosis by quality ensured sputumsmear microscopy, Standardized short-course anti-TB treatment (SCC) given under direct and supportive observation (DOT), a regular, uninterrupted supply of high quality anti-TB drugs and Standardized recording and reporting. ${ }^{2}$

In DOTS, during the intensive phase of treatment a health worker or other trained persons watch as the patient swallows the drug in his presence. During continuation phase, the patient is issued medicine for one week in a multi blister combi-pack of which the first dose is swallowed by the patient in the presence of health worker or trained person. The consumption of medicine in the continuation phase is also checked by the return of empty multi blister combi-pack, when the patient comes to collect medicine for next week. Drugs are provided in patient wise boxes with sufficient shelf life. In the program alternate day treatment is used. The cornerstone of successful DOTS therapy is adequate and regular drug intake. ${ }^{3}$

As the occurrence of TB is affected by socio-demographic profile of a patients and smoking is it's risk factor so an attempt is being made to describe the socio demographic profile and smoking \& drinking habits of patients attending DOTS centre of Rajendra Institute of Medical Sciences (RIMS), Ranchi in this study.

\section{Material \& Methods}

This was a cross sectional hospital based study conducted at the DOTS centre of RIMS, Ranchi. Total during of study was 3 months (August 2016 to October 2016). All patients registered for TB coming to DOTS Centre RIMS Ranchi from $16^{\text {th }}$ August 2016 to $15^{\text {th }}$ October 2016 and willing to participate in our study were 
selected. A total of 211 patients were selected consecutively for the study. Templates were generated on MS Excel sheet and data was analyzed using SPSS software (version 20).

\section{Results}

Out of 211 subjects studied most common affected age group was 21-40 years (48.82\%) followed by 40-60 years (25.12). More than 2/3 rd of the patients were male (71.57\%) and from rural area $(72.99 \%)$. Overcrowding was present in the house of $68.25 \%$ patients. Most patients were having primary level of education (43.6\%) and belonged to Class V of Socio Economic Status (55.46\%). Nature of occupation of patients of DOTS centre has been depicted in Table 2. We found that industrial workers were most affected group $(32.7 \%)$ followed by labors $(29.85 \%)$. Out of 211 study subjects $56.4 \%$ were smokers and $42.19 \%$ were alcoholics.

Table 1: Socio-demographic profile of DOTS patients

\begin{tabular}{|c|c|c|c|}
\hline & & Frequency $(\mathrm{n}=211)$ & Percentage (\%) \\
\hline \multirow[t]{2}{*}{ Gender } & Male & 151 & 71.57 \\
\hline & Female & 60 & 28.43 \\
\hline \multirow[t]{4}{*}{ Age } & $<20$ years & 30 & 14.22 \\
\hline & $21-40$ years & 103 & 48.82 \\
\hline & $41-60$ years & 53 & 25.12 \\
\hline & $>60$ years & 25 & 11.84 \\
\hline \multirow[t]{2}{*}{ Ethnicity } & Tribal & 40 & 18.96 \\
\hline & Non-Tribal & 171 & 81.04 \\
\hline \multirow[t]{2}{*}{ Residence } & Rural & 154 & 72.99 \\
\hline & Urban & 57 & 27.01 \\
\hline \multirow[t]{5}{*}{ Literacy } & Illiterate & 37 & 17.54 \\
\hline & Primary & 92 & 43.6 \\
\hline & Secondary & 50 & 23.7 \\
\hline & Higher Secondary & 32 & 15.16 \\
\hline & Graduation \& above & 0 & 0 \\
\hline \multirow{5}{*}{$\begin{array}{l}\text { Socio-economic } \\
\begin{array}{l}\text { Modified Batus } \\
\text { classification April 2016) }\end{array}\end{array}$} & Class I & 0 & 0 \\
\hline & Class II & 0 & 0 \\
\hline & Class III & 19 & 9 \\
\hline & Class IV & 75 & 35.54 \\
\hline & Class V & 117 & 55.46 \\
\hline \multirow{2}{*}{ Overcrowding at home } & Present & 144 & 68.25 \\
\hline & Absent & 67 & 31.75 \\
\hline
\end{tabular}

Table 2: Occupation of patients attending DOTS centre

\begin{tabular}{|l|l|l|}
\hline Occupation & Frequency $(\mathbf{n}=\mathbf{2 1 1})$ & Percentage $\mathbf{( \% )}$ \\
\hline Government Job & 4 & 1.9 \\
\hline Private Job & 9 & 4.26 \\
\hline Industrial Workers & 69 & 32.7 \\
\hline Agricultural Workers & 35 & 16.59 \\
\hline Labor & 63 & 29.85 \\
\hline Others & 31 & 14.7 \\
\hline
\end{tabular}

Others - Drivers, self employed etc.

Table 3: Smoking and Drinking Trends of DOTS patients

\begin{tabular}{|l|l|l|l|}
\hline Trend & & Frequency $(\mathbf{n = 2 1 1})$ & Percentage (\%) \\
\hline \multirow{2}{*}{ Smoking } & Smoker & 119 & 56.4 \\
\cline { 2 - 4 } & Non-smoker & 92 & 43.6 \\
\hline \multirow{2}{*}{ Alcohol Intake } & Alcoholic & 89 & 42.19 \\
\cline { 2 - 4 } & Non-Alcoholic & 122 & 57.81 \\
\hline
\end{tabular}

\section{Discussions}

In a similar study done by Jethani . S. et al, $74.9 \%$ subjects were male whereas $26.1 \%$ were females. ${ }^{4}$ In comparison to that, in our study male subjects were $71.56 \%$ and female subjects were $28.43 \%$.Mohsin et al's study conducted in Karachi found that $48.8 \%$ subjects were addicted to smoking and $38.83 \%$ subjects were alcoholics. ${ }^{5}$ In our study, $56.39 \%$ subjects were smokers and $42.18 \%$ subjects were alcoholics.In another study conducted by Department of Community Medicine RIMS Ranchi Jharkhand India it was found that, smear positive cases maximum were from age group more than 65 years $(62.5 \%){ }^{6}$ In our study the maximum number of smear positive cases were found to be among the age group of $21-40$ years $(48.81 \%)$. 


\section{Conclusion}

In our study we concluded that TB is far more common in males and the disease is more prevalent in the age group of $20-40$ years. Majority of the patient belong to rural background and were of non tribal ethnicity. Most of the patient had received primary education and were industrial workers. Most of the households were overcrowded. Almost half of the patients were of low socio economic status. Approximately half of the patients were addicted to smoking.

\section{Acknowledgements}

We are thankful to our faculty members for their proper guidance and the students of $7^{\text {th }}$ semester Abhijeet, Kumar Saurabh, Prerna, Swati, Jaideep and Nitish for their help \& support. We also thank staffs of DOTS Centre, RIMS, Ranchi.

\section{Financial support and sponsorship}

Nil

\section{Conflicts of interest}

There are no conflicts of interests.

Ethical Approval

The study was approved by Institutional Ethics Committee.

[1]. http://www.who.int/gho/tb/en/

\section{References}

[2]. http://www.searo.who.int/tb/topics/what_dots/en/

[3]. Park's Textbook of Preventive \& Social Medicine, pg 188. $23^{\text {rd }}$ Edition

[4]. Jethani S, Semwal J, Kakkar R, Rawat J. Study of Epidemiological Correlates of Tuberculosis, Indian Journal of Community Health, 2012; 24 (4):304-309.

[5]. Mohsin Sohail Siddiqui, Hafiz Abdul Moiz Fakih, Waqas Ahmed Burney, Razia Iftikhar, Nazeer Khan. Environmental and host related factors predisposing to TB in Karachi; A Cross Sectional, J Pak Med Stud, 2011;1 (1):13-18.

[6]. Sunderam Shalini, Kumari Sneha, Haider Shamim, Kashyap Vivek and Singh Shashi. International Journal of Interdisciplinary and Multidisciplinary Studies (IJIMS), 2015; 2(5) :119-127. 